\title{
The social and psychological adjustment of the Bulgarian community in Greece
}

\author{
Orestis Giotakos*, Constantina Pappa, Milena Nikova, Panagiota Koutsiafti, \\ Vera Laggari, Zoe Goula, Maria Keramida, Sotiria Goula, \\ Konstantina Gianniri and Kyriakos Katsadoros
}

Address: Day Center "Omonoia", Greece

* Corresponding author

from International Society on Brain and Behaviour: 2nd International Congress on Brain and Behaviour

Thessaloniki, Greece. 17-20 November 2005

Published: 28 February 2006

Annals of General Psychiatry 2006, 5(SuppI I):SI I5 doi:I0.II86/I744-859X-5-SI-SII5

\section{Background}

Past studies on immigration and mental health indicate that immigration can have a significantly negative effect on the psychological well-being of a person.

\section{Materials and methods}

In the present study, 200 Bulgarian immigrants currently living in Athens took part. Their age ranged from 18 to 65 years, $18 \%$ of them were men and $78 \%$ women, while the average stay in Greece is 5.1 years. The questionnaire that was filled in for the purpose of the study was divided into three main sections. The first part concerned personal details, the second section questioned the access to the social services and the third one comprised the Zung Depression Inventory.

\section{Results}

It was found that the mean duration of occupation was 16.8 hours and the average income 636 euros. $78 \%$ of the sample, reported unsatisfied from the social services, $50 \%$ unsatisfied from the health services and $45 \%$ from the educational system of Greece. In addition, almost 50\%, reported that prefers social interaction with their copatriots. According to the Zung Depression Inventory, 53\% could be classified as highly depressed and $18 \%$ as mildly depressed. Finally, psychological symptoms and depression correlated significantly with occupation and access to an adequate social network.

\section{Discussion}

In conclusion, it seems that in this sample of Bulgarian immigrants, unfulfilled expectations and inadequate social support induce symptoms of psychological distress and depression.

\section{References}

I. Fazel M, Wheeler J, Danesh J: Prevalence of serous mental disorder in 7000 refugees resettled in western countries: A systematic review. The Lancet 2005, 365:|309-|3|4. 